\title{
Frontiers in endovascular and interventional neurology (FEIN): grand challenges - looking ahead
}

\author{
Osama O. Zaidat ${ }^{1,2,3 *}$ and Camilo R. Gomez ${ }^{4}$ \\ 1 Department of Neurology, Medical College of Wisconsin and Froedtert Hospital, Milwaukee, WI, USA \\ 2 Department of Neurosurgery, Medical College of Wisconsin and Froedtert Hospital, Milwaukee, WI, USA \\ ${ }^{3}$ Department of Radiology, Medical College of Wisconsin and Froedtert Hospital, Milwaukee, WI, USA \\ ${ }^{4}$ Alabama Neurological Institute, Birmingham, AL, USA \\ *Correspondence: szaidat@mow.edu
}

"If you have a task to perform and are vitally interested in it, excited and challenged by it, then you will exert maximum energy. But in the excitement, the pain of fatigue dissipates, and the exuberance of what you hope to achieve overcomes the weariness" Jimmy Carter.

With great challenges comes great opportunities and we personally are greatly optimistic about the prospect of field of endovascular and interventional neurology field. This field has been paved by pioneers from Neurology, Neurosurgery and Radiology worldwide who put us at a very unique stage ready for the next level of achievements and milestone by motivated neuro-interventionalist, vascular neurologists, neuro-intensivists and vascular neurosurgeons worldwide.

The past two decades have seen the rise of Neuro-interventional specialty and discipline worldwide, especially with in United States and Europe. Simultaneously we have seen a greater number of clinician such as neurologists and neuro-surgeons becoming neuro-interventionalists; joining the interventional neuro-radiologist colleagues in the endovascular management of cerebrovascular diseases.

Back in 1991 it was estimated that only five neurologists were performing interventional procedures but today Society of Vascular and Interventional Neurology (SVIN) has registered around 100 neurointerventional Neurologists and about 10-12 are being trained every year. Most neurologists were trained by interventional neuro-radiologists and endovascular neuro-surgeons. Today, the field is advanced by all three specialties.

Moreover, the advances and remarkable achievement in the field would have not been possible without the scientific contribution of the three specialties as well as the vascular neurologists, who are advancing the field with randomized controlled trials such as the PROACT, MELT, IMS, and ISAT trials to promote evidence based medicine in the neuro-interventional procedures. (Furlan et al., 1999; Molyneux et al., 2002; IMS II Trial Investigators, 2007; Ogawa et al., 2007) Such trials take the field to new frontiers that would excel the clinical practice and move it forward.

The following are some of the short and long term challenges the field of neurointervention, endovascular and interventional neurology need to over come.

\section{PRACTICE, PERFORMANCE, AND TRAINING GUIDELINES - MULTISPECIALTY AND MULTINATIONAL COLLABORATION}

Due to lack of clear outcome data and clinical evidence; the field would benefit from multispecialty and multinational collaboration on creating and defining important guidelines, consensus experts' agreement and benchmarks. Example of such guidelines including those published by multi society about training standards for acute ischemic stroke endovascular therapy and neuro-interventional procedures performance guidelines. (Qureshi et al., 2008; Meyers et al., 2009) Hospital administrators, physicians, and insurance companies are looking for performance and quality standards. Existing ones need periodical update every $3-5$ years to assure inclusions of new advances in science and device development. Accreditation and training standards for the sub-specialty need to be pushed forward in a multispecialty collaborative fashion. The quality of procedure depends on the selection of patients by vascular neurologists, neuro-interventionalist skills, the infrastructure, and postprocedure care provided by neuro-intensivists. Without proper oversight; the centers performing Neuro-endovascular procedure may not meet quality benchmark, and the neurointerventional field might suffer. All these standards and guidelines documents should be produced in multilateral and multinational approach taken into consideration the accepted scientific method in establishing such standards.

\section{CLINICAL EVIDENCE AND TRIALS - DESIGNING, IMPLEMENTING AND FUNDING}

The current retrospective and prospective observational neuro-interventional studies provide the basis for clinical trial in forms of both providing preliminary data of hypothesis testing and formulating the definitive framework for clinical trial which will form the basis of advancing the field forward. The bulk of evidence of neurointerventional procedure currently consists of retrospective studies, prospective registries and safety and feasibility trails. The four aforementioned trials are landmarks in the field and more are on the way. (Furlan et al., 1999; Molyneux et al., 2002; IMS II Trial Investigators, 2007; Ogawa et al., 2007) Not only we are in dire need of clinical trials but also we need to push for standardization on national and international level for the funding of these clinical trials.

With the introduction of this journal and others the field of neuro-intervention would benefit with there own avenues to make current research more accessible.

\section{INFRASTRUCTURE AND MANPOWER - CLINICAL EFFECTIVENESS VERSUS COST EFFECTIVENESS}

Neuro-interventional procedures are very costly in infrastructure requiring millions of dollars; and in a highly specialized manpower which also comes with a price tag. The challenge is to communicate with hospital administrators to invest in Neurointerventional services as these services 
are important for patients and life saving. The challenge is to make such an expensive mean of therapy more affordable worldwide is beyond the scope of this introductory paper and needs collaboration of industry hospitals and insurance carrier.

\section{INNOVATING NEURO-INTERVENTIONAL DEVICES - INCREASING SAFETY AND REDUCING COMPLICATION}

There is still a large room for improvement in practically all aspects of Neurointerventional devices including acute ischemic stroke devices and clot retrievers, stents for atherosclerotic disease, coiling for cerebral aneurysm and vascular malformation endovascular therapy. Creativity and introduction of different concepts in designing the Neurointerventional devices of the future are keys to improve safety and feasibility of neuro-interventional procedures and subsequent widespread use. The current limitations of devices require improvement in deliverability, trackability, flexibility and most importantly effectiveness versus safety balance. The number of potential neurovascular procedure may be small in comparison to other medical areas, which may limit the potential interest in device development.

\section{EMBRACING INTERVENTION - CHANGING STATUS QUO}

This related to other challenges that face field of advancing the scientific evidence and device development. The vascular neurologists, neuro-intensivists, neurohospitalists, neuro-surgeons, emergency room physicians, and primary care providers are slowly realizing the benefit of minimally invasive procedures to treat cerebrovascular diseases. More education and awareness is still needed.

\section{BASIC SCIENCE RESEARCH}

The basic science research in the field is costly and time consuming. National and international scientific agency needs to dedicate financial support to advance the basic science of neuro-interventional procedures such as stem cell delivery to treat ischemic stroke and vascular angiogenesis inhibitors delivered via endovascular technique to treat vascular malformation.

\section{LONG TERM CHALLENGES AND FUTURE ENDEAVORS}

The above challenges are a part of what the future may bring in with integration of neuro-protective agents with neurointervention and other innovative ideas and breakthroughs in the field of neurocritical care and vascular neurology. New changes may transform the field to neurointervention. The future opportunities and challenges in endovascular and interventional neurology may be realized by scientific publications and communications among the peers and people interested in the field via publications and dissemination of knowledge.

The new journal; Frontiers in Endovascular and Interventional Neurology (FEIN) provides the platform for sharing the scientific advances, challenges, and both clinical and basic science data in the field of Vascular, Neuro-critical care and Interventional Neurology.

"We aim above the mark to hit the mark" - Ralph Waldo Emerson

\section{REFERENCES}

Furlan, A., Higashida, R., Wechsler, L., Gent, M., Rowley, H., Kase, C., Pessin, M., Ahuja, A., Callahan, F., Clark, W. M., Silver, F., and Rivera, F. (1999). Intra-arterial prourokinase for acute ischemic stroke. The PROACT II study: a randomized controlled trial. Prolyse in Acute Cerebral Thromboembolism. JAMA 282, 2003-2011.
IMS II Trial Investigators. (2007). The Interventional Management of Stroke (IMS) II Study. Stroke 38, 2127-2135. [Epub 2007 May 24].

Meyers, P. M., Schumacher, H. C., Alexander, M. J., Derdeyn, C. P., Furlan, A. J., Higashida, R. T., Moran, C. J., Tarr, R. W., Heck, D. V., Hirsch, J. A., Jensen, M. E., Linfante, I., McDougall, C. G., Nesbit, G. M., Rasmussen, P. A., Tomsick, T. A., Wechsler, L. R., Wilson, J. R., and Zaidat, O. O., Writing Group for American Academy of Neurology, American Association of Neurological Surgeons Cerebrovascular Section, Society of Neurointerventional Surgery and Society of Vascular and Interventional Neurology (SVIN). (2009). Performance and training standards for endovascular ischemic stroke treatment. J. Stroke Cerebrovasc. Dis. 18, 411-415.

Molyneux, A., Kerr, R., Stratton, I., Sandercock, P., Clarke, M., Shrimpton, J., and Holman, R., International Subarachnoid Aneurysm Trial (ISAT) Collaborative Group. (2002). International Subarachnoid Aneurysm Trial (ISAT) of neurosurgical clipping versus endovascular coiling in 2143 patients with ruptured intracranial aneurysms: a randomised trial. Lancet 360, $1267-1274$

Ogawa, A., Mori, E., Minematsu, K., Taki, W., Takahashi, A., Nemoto, S., Miyamoto, S., Sasaki, M., and Inoue, T., MELT Japan Study Group. (2007). Randomized trial of intraarterial infusion of urokinase within 6 hours of middle cerebral artery stroke: the middle cerebral artery embolism local fibrinolytic intervention trial (MELT) Japan. Stroke 38, 2633-2639.

Qureshi, A. I., Abou-Chebl, A., and Jovin, T. G. (2008). Qualification requirements for performing neurointerventional procedures: a Report of the Practice Guidelines Committee of the American Society of Neuroimaging and the Society of Vascular and Interventional Neurology (SVIN). J. Neuroimaging. 18, 433-447.

Received: 09 June 2010; accepted: 09 June 2010; published online: 02 August 2010.

Citation: Zaidat OO and Gomez CR (2010) Frontiers in endovascular and interventional neurology (FEIN): grand challenges-looking ahead. Front. Neur. 1:13. doi: 10.3389/ fneur.2010.00013

This article was submitted to Frontiers in Endovascular and Interventional Neurology, a specialty of Frontiers in Neurology.

Copyright $\odot 2010$ Zaidat and Gomez. This is an open-access article subject to an exclusive license agreement between the authors and the Frontiers Research Foundation, which permits unrestricted use, distribution, and reproduction in any medium, provided the original authors and source are credited. 